\title{
It's Not All about the Economy Stupid! Immigration and Subjective Well-Being in England
}

\author{
Peter Howley ${ }^{1}$, Muhammad Waqas ${ }^{1}$, Mirko Moro², Liam Delaney ${ }^{3}$,Tony Heron ${ }^{4}$
}

While much is known regarding the effects of immigration for objective outcomes, relatively little is known regarding effects for perceived well-being. By exploiting spatial and temporal variation in the net-inflows of foreign-born individuals across local areas in England, we examine the relationship between immigration and natives subjective well-being as captured by the General Health Questionnaire (GHQ). We find small negative effects overall but that an analysis of main effects masks significant differences across sub-groups with relatively older individuals, those with below average household incomes, the unemployed and finally those without any formal educational qualifications experiencing much more substantive well-being losses than others. These observed well-being differentials are congruent with voting patterns evident in the recent UK referendum on EU membership. We put forward perceived as opposed to actual labour market competition and social identity as two potential explanations for the negative well-being impacts of immigration for natives.

Keywords: Immigration; mental health; social-identity; subjective well-being

1. Leeds University Business School, Leeds, United Kingdom

2. University of Stirling, Stirling, United Kingdom

3. School of Economics, University College Dublin, Ireland

4. Department of Politics, University of York, York. United Kingdom

Corresponding author

1. Dr. Peter Howley

Associate Professor in Economics

Economics Division

Leeds University Business School

Leeds

Email: p.howley@leeds.ac.uk

Acknowledgments: This project was funded by the Nuffield Foundation, but the views expressed are those of the authors and not necessarily those of the Foundation 


\title{
It's Not All about the Economy Stupid! Immigration and Subjective Well-Being in England
}

\begin{abstract}
While much is known regarding the effects of immigration for objective outcomes, relatively little is known regarding effects for perceived well-being. By exploiting spatial and temporal variation in the net-inflows of foreign-born individuals across local areas in England, we examine the relationship between immigration and natives' subjective well-being as captured by the General Health Questionnaire (GHQ). We find small negative effects overall but that an analysis of main effects masks significant differences across sub-groups with relatively older individuals, those with below average household incomes, the unemployed and finally those without any formal educational qualifications experiencing much more substantive well-being losses than others. These observed well-being differentials are congruent with voting patterns evident in the recent UK referendum on EU membership. We put forward perceived as opposed to actual labour market competition and social identity as two potential explanations for the negative well-being impacts of immigration for natives.
\end{abstract}

Keywords: Immigration; mental health; social-identity; subjective well-being; labour market competition 


\section{Introduction}

Following the 2004 enlargement of the European Union, the UK experienced a large influx of migrants from new EU member states (Czech Republic, Estonia, Hungary, Latvia, Lithuania, Poland, Slovakia and Slovenia - also known as the accession or A8 countries). The effect of this influx of new migrants on the UK economy has been the subject of intense political debate, and was one of the dominant issues in the recent UK referendum on EU membership. Yet much of the research that has been done in the UK suggests that immigration has had little, if any, negative impact on the labour market outcomes of natives and this finding is mirrored in much of the research outside the UK (Card, 2005; Dustmann et al., 2013; Lemos and Portes, 2013)

In public discourse, immigration is also often associated with increased burdens on taxpayers through rising health care costs and demand for social services. Again, the available evidence suggests that migrants are typically younger and healthier, and in turn more likely to be at work (hence less likely to access social services) than the native UK population. In effect, it is likely that they not only pay their own way, but also partly subsidise the costs of public services for others (Dustmann et al., 2010). Such findings, coupled with increasing worries over immigration expressed by many during the recent EU referendum campaign in the UK, as well as the rise of far-right populist parties with an antiimmigration stance throughout Europe, leads us to question if there are other pathways by which inflows of migrants affects the well-being of natives. Within this context, rather than focusing on economic outcomes such as labour market impacts, the main aim of this work is to examine the impact of immigration on the subjective well-being of natives.

Considering the population as a whole (main effects), we find using both a fixed-effects (following the same individuals over time) and instrumental variable specification (quasi-natural experiment) that net inflows of foreign-born individuals into local areas are associated with negative (albeit relatively small) subjective well-being impacts for natives. These negative impacts are much more substantive, 
however, for certain groups such as relatively older individuals $(60+)$, the unemployed, those with below average household incomes and finally those without any formal educational qualifications. On the other hand, the subjective well-being of non-UK born natives appears to be enhanced by inflows of migrants. We put forward perceived as opposed to actual labour market competition and social identity as two of the factors underpinning these results.

\section{Previous research relating to the relationship between immigration and subjective well-being}

While there is a rich literature investigating the impact of immigration on objective measures of wellbeing such as labour market outcomes, research examining the relationship between immigration and subjective indicators of well-being is relatively sparse. The studies in this area most closely related to our own work are Akay et al. $(2014 ; 2017)$ and Ivlevs and Veliziotis $(2018)$ both of which examined the relationship between immigration and self-reported life satisfaction. In what is perhaps the first study in this area using panel-data methods, Akay et al. (2014) and Akay et al. (2017) in influential work in Germany, found using the German Socio-economic Panel a positive relationship between both immigration and ethnic diversity with the life satisfaction of natives. These effects were largely driven by the relatively younger age-cohorts as they found no significant relationship for those over 50 . Given that the composition, rate of change as well as attitudes towards migrants may differ, the relationship between immigration and well-being may, however, be different in the UK than that observed in Germany (see Giuletti, 2017).

Bearing this in mind, if we look at research in the UK, it is interesting to observe that Ivlevs and Veliziotis (2018) employed a similar methodology to that of Akay et al $(2014 ; 2017)$, but observed no significant main effect when it comes to the relationship between inflows of people from the A8 accession countries ${ }^{1}$ and the life satisfaction of natives. A different picture did emerge, however, when they looked specifically at various sub-groups. Here they find some evidence to suggest that increases in the A8 migration inflow rate is negatively associated with the life satisfaction of relatively 
older, lower-income, and unemployed individuals, but positively related with the life satisfaction of their younger and wealthier counterparts.

The main objective of this research is also to examine the relationship between immigration and subjective well-being. We follow a similar strategy to that employed by Ivlevs and Veliziotis (2018) in the UK and also that by Akay et al. $(2014 ; 2017)$ in Germany, but with some key differences. First, by concentrating on the British Household Panel Survey (BHPS), Ivlevs and Veliziotis (2018) were constrained to a relatively short time period, namely 2003-2008 (immediately before and after the $2004 \mathrm{EU}$ enlargement), and as such it is possible that their estimates capture the effect of an initial migration shock due to the A8 accession. By merging the BHPS with the UK Household Longitudinal Survey (UKHLS) our work is based on a much larger sample period ranging from 2000 to 2017.

A further key difference between our own work and that of existing research relates to our identification strategy. Specifically, we adopt two different estimators (panel models with individual fixed-effects and an instrumental variable approach) as well as a battery of sensitivity tests to address any remaining concerns surrounding, for example, residential sorting. In the first case, the effect of immigration in our main fixed-effects model of subjective well-being is identified only when it changes for the same individual, and after controlling for a rich set of time-varying factors at both the individual, neighbourhood and national level. In the second case, we instrument our measure relating to numbers of foreign-born individuals living in local areas with an exogenous predicted value based on prior settlement patterns. The combination of these approaches will help account for any endogeneity issues that may have been a factor in previous work.

Finally, we estimate the effect of net inflows of foreign-born individuals (migrants) on subjective wellbeing as captured by the General Health Questionnaire (GHQ) as opposed to self-reported life satisfaction. The original General Health Questionnaire (GHQ) measure was initially conceived as a 
screening instrument for psychiatric disorders (e.g. see Goldberg and Hillier, 1979), but the version used in this study consists of a shorter 12 item scale and is commonly used as a general measure of subjective well-being. The main advantage of the GHQ as is that it is based on responses to 12 separate questions as opposed to one singular measure of life satisfaction.

\section{Why would immigration affect perceived well-being?}

We put forward two potential factors, namely economic self-interest and social identity to explain why immigration may have subjective well-being consequences for natives. When it comes to economic self-interest, there is a rich economic literature concerned with establishing the effects of inflows of migrants for labour market outcomes. Intuitively, one can imagine that inflows of migrants may be a source of competition for natives (especially lower-skilled workers) thus lowering wages and lessening employment opportunities. Despite the intuitive appeal of this line of argument, empirical evidence on the whole would suggest that immigration is associated with little if any ${ }^{2}$ changes in wages (e.g. see Card, 2005; Dustmann et al., 2013; Lemos and Portes, 2013).

In public discourse, it is also commonly argued that immigration is a drain on public finances. The available evidence would suggest, however, that migrants make a substantive net positive fiscal contribution overall (Dustmann and Frattini, 2014). While there is a lack of clear evidence relating to a negative effect for either labour market outcomes or public finances, natives themselves may still feel that inflows of migrants lessens their employment opportunities or increases their taxes due to, for example, social welfare spending. Thus inflows of migrants could be a source of psychological distress for natives based on the belief that it lowers their economic opportunities. Two issues highlighted recently in this journal which might help fuel this belief is that migrant workers are more likely to be over-qualified for their job (Sirkeci et al., 2018) and have lower absence from work rates, at least in the short run (Dawson et al., 2018). 
Social identity theory offers another platform for explaining why immigration may affect native wellbeing. Social identity theory developed from the early work of Tajfel (1974), in order to explain intergroup behaviour. The theory postulates that groups to which people belong (e.g. country of birth) can be an important source of pride and self-esteem, thus fostering psychological well-being (Haslam et al., 2009). The central hypothesis behind this theory is that in order to increase their own self-image, people will often boost the status of (and sense of belonging to) their own ingroup, in order to discriminate against a contrasting outgroup to which they do not belong. Examples of group membership include: fandom of a sports team, local community, or what is of relevance for this study, nation state.

In keeping with this theory, native individuals who strongly identify with characteristics that define others in their native ingroup such as ethnic background may be relatively more likely to perceive migrants as belonging to an outgroup. People engage in social comparisons and think more positively of the ingroup (other natives) and more negatively of the out-group (immigrants). This can lead to a favourability gap between their ingroup whom they find to be esteemed, thereby creating a positive identity, and a disliked outgroup who they may see as being less trustworthy (Mangum and Block, 2018). Inflows of migrants can, in turn, act to destabilise the social identity and subsequently wellbeing of ingroup natives, because it may threaten the boundaries between ingroup and outgroup via the process of acculturation (see van der Zee et al., 2016). It has been suggested, for instance, that pressure to assimilate / integrate (e.g. due to policies, or shifting social norms) and give up one's sense of ethnic identity may result in anger, depression, or even violence (Phinney, et al., 2001).

Building on the discussion above, we hypothesise that both perceived economic impacts and social identity will play a role in predicting the degree to which natives are impacted, in subjective well-being terms, by inflows of migrants. As a way to test our idea relating to perceived economic impacts, we examine if changes in GDP moderates the subjective well-being effects associated with inflows of 
migrants. Our rationale being that natives are more likely to perceive migrants as an economic threat when economic conditions are relatively less favourable. In relation to social identity, we hypothesise that on the basis of cultural similarities, non-UK born residents will be relatively less likely to perceive migrants as part of an 'outgroup' than UK born ones. In turn, if inflows of migrants negatively impacts the subjective well-being of natives, our a priori expectation is that these effects will be more apparent for UK as opposed to non-UK born residents.

\section{Methods}

Our study uses information from two longitudinal British surveys, namely the British Household Panel Survey (BHPS) and its successor, the UK Household Longitudinal Survey (UKHLS). These surveys collect, on an annual basis, information relating to individual's subjective well-being, together with numerous other individual characteristics. We restrict our analysis to the period 2000 until 2017, as the year 2000 was the earliest date in which we have annual data relating to numbers of foreign-born individuals living in local authority areas in England.

\section{Outcome Variables}

The indicator of subjective well-being we use as our key outcome variable is the General Health Questionnaire (GHQ) which consists of a 12 item scale (see Table A1 in the appendix). Each item is accompanied by four possible responses: two of the answers are positive and two are negative. A score ranging from 0 (best) to 36 (worst) is computed for each individual in the survey - the higher the score then the more likely it is that respondents are suffering from some form of psychological distress. For simplicity, we reorder this variable so that individuals are scored from 0 (worst) to 36 (best), and label this variable as subjective well-being.

\section{Measure of inflows of foreign-born individuals (migrants)}

Through a special license application, we obtained a geographic identifier pertaining to which local 
authority area each individual in our household surveys belongs (BHPS and UKHLS). Using this geographic identifier, we spatially linked our longitudinal household survey datasets recording individuals' subjective well-being with information from the Office for National Statistics (ONS), relating to estimated numbers of foreign-born individuals living in their local authority area. There are 391 local authorities in the UK. The ONS bases these estimates on the UK Annual Population Survey which is the largest survey in the UK consisting of 320,000 respondents (see Figure A1 in the appendix for a visual illustration of how numbers of migrants have changed over time). Like our household surveys recording individual well-being, this information from the ONS is available on an annual basis. The end result of this data linkage is that we can relate changes in individuals' subjective well-being as captured by the $\mathrm{GHQ}$, to changes in the numbers of foreign-born individuals living in their local area.

\section{Key controls}

We merged our household survey datasets with the English Indices of Multiple Deprivation provided by the Department for Communities and Local Government. These Indices of Multiple Deprivation allow us to control for any differences in economic and social deprivation across neighbourhoods (see A2 in the Appendix for more details). We supplemented this measure with region dummies. ${ }^{3} \mathrm{~A}$ detailed set of individual controls were also included in the analysis (see Table A3 in the appendix for relevant summary statistics). Additionally, in order to control for any macro and period-specific changes, we added in wave dummies ${ }^{4}$ and a measure of annual GDP growth. Lastly, to account for any potential heteroscedasticity or serial correlation, we used cluster robust standard errors (clustered at the individual level). ${ }^{5}$

\section{Empirical Specification}

The analysis begins by assuming that subjective well-being of individual $i$ living in local authority $/$ at time $t\left(W_{i t t}\right)$ is explained by a vector of socio-economic and demographic characteristics $\left(X_{i t}\right)$ (including 
labour force status), neighbourhood deprivation $\left(N D_{I t}\right)$, annual GDP growth at the national level $\left(G D P_{t}\right)$ and changes in the number of foreign-born individuals living in each local authority area $\left(F B_{/ t}\right)$. This yields the following explanatory model where $a_{i}$ is the individual fixed effect and $v$ and $r$ are a set of wave and region dummies:

$$
W_{i l t}=\beta_{0}+\beta_{1} X_{i t}+\beta_{2} N D_{l t}+\beta_{3} G D P_{t}+\beta_{4} F B_{l t}+a_{i}+v_{t}+r+\varepsilon_{i l t}
$$

The aim of this fixed-effects analysis is to give us an initial understanding of the impact of changes in the number of foreign-born individuals living in each local authority area on the subjective well-being of natives living in the host communities. Here we define natives as individuals born in the UK. Later we also examine to what extent inflows of foreign-born individuals affect the subjective well-being of non-UK born residents.

It is worth noting that our use of fixed-effects will account for any unobserved heterogeneity that is time-invariant at the individual level. Macroeconomic conditions are accounted for by including annual GDP growth; other general trends and factors common to our sample of respondents are also captured by our wave dummies $(v)$. Furthermore, we control for a wide array of both individual level controls, and neighbourhood deprivation, which helps us account for any time-variant sources of heterogeneity at the individual or local level. Still it is possible that our regression estimates may still affected to some degree by endogeneity issues such as measurement error as the ONS data relating to numbers of foreign-born individuals in each local authority area are estimates based on annual population surveys, albeit these are large-scale surveys and so any measurement error is likely to be small.

One mechanism to account for any remaining endogeneity issues would be to adopt an instrumental variable approach and in this study we rely on an instrumental variable strategy based on past settlement patterns first developed by Card and DiNardo (2000) and Card (2001) (see A4 in the appendix for more details). The idea behind this instrument is that independent of any differences in 
economic opportunities, migrants will be more attracted to certain areas over others based on the settlement patterns of past migrants. Thus prior settlement patterns will help predict future inflows and this predicted value, in turn, will serve as a suitable instrumental variable for actual current inflows of foreign-born individuals into local areas.

To implement this approach in our study, first we obtain data relating to the concentration of migrants in each local authority area from the 2001 and 2011 Censuses. Next we use this information to obtain the 'predicted' numbers of foreign-born individuals in each local authority area to use as an instrument for the actual number. The predicted number is simply obtained by redistributing the total numbers of migrants, based on the prior settlement patterns evident from past censuses (see A4 in the appendix for more details in relation to the derivation of this instrumental variable).

\section{Results}

Main effects

Table 1 presents the main effect estimates relating to the impact of immigration on the subjective well-being of natives in England. ${ }^{6}$ The results relating to our control variables are all along expected lines (see Dolan et al. 2008) and are reported in Table A5 in the Appendix and so for parsimony are not discussed. The first specification outlines the results from a pooled cross-sectional model, whereas in the second column we take advantage of the panel nature of the dataset by employing individual fixed-effects. We label our key explanatory variable of interest as foreign-born individuals (measured in ten thousands). This variable captures the relationship between changes in the numbers of people born outside the UK living within each local authority area (net inflows of migrants), and the subjective well-being of natives (UK-born individuals) already living in those areas. Our specifications include a full set of individual characteristics (including labour force status), national GDP, wave and region dummies and a neighbourhood deprivation rank. 
In our pooled cross-sectional model, foreign-born individuals attracted a positive coefficient (0.003) but one that was close to zero and not statistically significant. For specification two, where we took advantage of the longitudinal nature of our datasets by employing individual fixed-effects, foreignborn individuals attracted a negative and statistically significant coefficient $(-0.025, p=0.054)$. One potential explanation for the difference between our pooled cross-sectional and fixed-effects specifications is that immigrants are relatively more likely to locate in prosperous areas, and these differences are absorbed by the fixed-effects, but not adequately controlled for in the pooled crosssectional analysis.

In our fixed-effects specification, the effect of foreign-born individuals on subjective well-being is identified only when it changes for the same individual, and after controlling for a rich set of timevarying factors at both the individual and the neighbourhood level. Therefore any potential problems relating to selection bias is substantially mitigated. That being said, the interested reader is referred to Appendix A6 where we discuss the issue of selection bias in more detail and conduct a series of robustness checks to further rule out the possibility that our coefficient estimates are significantly affected by this issue. In short we tested the sensitivity of our main estimates to additional specifications where we added in an additional covariate to capture individuals who moved neighbourhoods and second simply excluded all individuals who moved neighbourhoods during our study period. We also provide some evidence to suggest that immigration is unlikely to be an important factor in the residential choices of natives.

\section{Insert table 1 here}

\section{Differences across sub-groups}

As illustrated in Table 2, the impact of foreign-born individuals varies substantively across different sections of the population. ${ }^{7}$ First looking at age, we found that the estimated effect of foreign-born individuals for those over 60 years of age was just over three times as large as the estimated impact when looking at the population as a whole $(-0.084, \mathrm{p}=0.008) \cdot{ }^{8} \mathrm{~A}$ similar picture emerges when we 
just focused on the over 70s, only this time foreign-born individuals attracted a coefficient that was almost six times as large $(-0.142, p=0.002)$.

There also appears to be some significant differences across income groups. When looking at individuals in the lowest quartile of the household income distribution, foreign-born individuals was associated with a negative and statistically significant coefficient $(-0.062, p=0.061)$ and one that was two and a half times that observed when looking at the population as a whole ${ }^{9}$. The estimated coefficient for individuals with below median household income was also negative and statistically significant, but smaller $(-0.040, p=0.077)$ than that observable when looking at those in the lowest quartile. All this suggests that the population-level effects outlined in Table 1 masks significant age and income group heterogeneity in the relationship between immigration and subjective well-being.

Next we examined if there were any differences across education groups. Foreign-born individuals attracted a negative and statistically significant coefficient $(-0.138, p=0.001)$ for the group of individuals without a formal educational qualification (degree or higher is the reference category) and one that was approximately five times as large as that observed for the population as a whole. The other education groups attracted coefficients that were much smaller in size and not statistically significant. Table 2 also presents a comparison between those in full time employment and the unemployed. When we just focused on those in full time employment, the observed relationship between foreign-born individuals and subjective well-being was negative but not statistically significant. On the other hand, when we restricted our analysis to the unemployed, foreign-born individuals attracted a negative and statistically significant coefficient $(-0.146, p=0.067)$ and one that was almost six times as large as that observed when looking at the population at a whole. ${ }^{10}$ Finally, we found no significant gender differences in the relationship between foreign-born individuals and subjective well-being.

Insert table 2 here 


\section{Communicating effect sizes}

The analysis in the preceding section suggests that for certain sub-groups of the population, rising numbers of foreign-born individuals living in local areas has had a detrimental impact on subjective well-being. The question remains how large are these effects? For illustrative purposes, we compared estimated effect sizes to that of other commonly observed negative correlates with subjective wellbeing, namely divorce and unemployment. We emphasise, however, that the following interpretation needs to be taken cautiously as it is hard to compare effect sizes of personal characteristics with a contextual variable such as the number of foreign-born individuals living within a local authority area. We can see in the second column of Table A5 in the Appendix that being divorced, as opposed to being single, was associated with a -0.396 unit reduction in subjective well-being, whereas unemployment as compared to paid employment was associated with a -1.677 unit reduction. This is in keeping with much previous research which suggests that unemployment alongside disability is associated with the largest reductions in subjective well-being (for further insight on labour market statuses and wellbeing, see, Kamerāde and Bennett, 2018; Nordenmark, 1999; Strandh, 2000), whereas the adverse well-being effects associated with divorce while still significant and substantive is typically more modest.

In the year 2000 , the mean number of foreign-born individuals living in local authority areas for respondents in our sample came to 15,689 , whereas in 2016 the mean number had increased to 42,606 . We used this mean level change $(26,917)$ as a reference point, and found that such a change translated into an average well-being loss of -0.07 units $\left(2.6917^{*}-0.025\right)$ for natives. This is equivalent to 18 and 4 percent of the estimated well-being losses from divorce and unemployment for the population as a whole. This would suggest that, for the population as a whole, the impact of immigration for subjective well-being is relatively weak. The impact, however, of immigration is much more notable for certain cohorts. Looking at the over 60 s, for instance, we found that such a change would be equivalent to 58 and 14 percent, whereas for the over 70 s the estimated well-being losses 
were found to be broadly equivalent to the estimated well-being losses from divorce for the population as a whole (96\%) and 23 percent of the estimated well-being effects from unemployment. It is worth noting at this stage that an increase of 26,917 in the number of foreign-born individuals in a local authority area is by no means an extreme scenario, as 30\% percent of the current UK population live in a local authority area which has experienced a change in excess of this during the study period.

After restricting our analysis to those in the lowest quartile of household income, we found that the estimated well-being losses came to 43 and 10 percent of the estimated well-being losses from divorce and unemployment respectively for the population as a whole. For the unemployed, the estimated effects are somewhat larger (-0.39 unit reduction) which is equivalent to 99 and 23 percent of the estimated impact of divorce and unemployment. Taken as a whole, the figures above suggest that the overall well-being impact of immigration is relatively small but that there are more notable well-being effects for certain sub-groups, namely older, poorer, unemployed and relatively less well-educated individuals.

\section{Robustness checks}

Instrumental variable analysis

To address any concern that our fixed-effects estimates are affected by remaining endogeneity issues we instrumented foreign-born individuals with an exogenous predicted value based on prior settlement patterns. Specification 3 in Table 1 presents the results from this instrumental variable analysis. ${ }^{11}$ The coefficient for foreign-born individuals is negative, statistically significant and is very similar to that obtained in our fixed-effects specification $(-0.032 \vee-0.025)$. Next we re-ran our subgroup analysis outlined in Table 2 using our instrumental variable (IV) specification. The point estimates are somewhat larger than that observed in the fixed-effects analysis but notwithstanding this point, the estimates across both our fixed-effects and instrumental variable specifications are as a whole remarkably similar. As a further robustness check, instead of obtaining a predicted value 
based on prior settlement patterns evident from using both the 2001 and 2011 census, we just used the 2001 census. Again we found that the estimates were remarkably similar across both specifications (see Table A7 in the appendix for a direct comparison between the different IVs).

Additionally, we repeated the IV analysis, but this time just focused on observations from the UKHLS during the 2010-2017 period and again used the 2001 census as the basis for deriving our instrumental variable (predicted migrants value). The advantage of this approach is that it allows a minimum of 9 years but rising to 16 year time gap between the data used to generate our predicted value and actual inflows of migrants. Using this approach lessens the possibility that our instrument is significantly correlated with unobserved persistent local conditions. We found no significant difference between our IV estimates when we restricted the analysis to the $2010-2017$ period $(-0.032 \vee-0.035) .{ }^{12}$

\section{Sensitivity checks}

As a sensitivity check, instead of using aggregate numbers of foreign-born individuals (net inflows) as our key explanatory variable, we also used migrant share. Migrant share was simply derived by dividing the total numbers of foreign-born individuals by the total population in each local authority area. ${ }^{13}$ In Table 2 we can see that our results when using migrant share as our key explanatory variable followed the same general pattern as that observed when using foreign-born individuals both in terms of overall population level effects and our sub-group analysis.

\section{What can explain these results?}

\section{Perceived labour market competition}

Our sub group analysis earlier, specifically our findings that the negative subjective well-being effects associated with inflows of foreign-born individuals are larger for the unemployed and those in relatively lower educational groupings, provide some support for our conjecture that perceived labour market threats may be a factor behind our results. This is because it seems reasonable to suggest that 
these groups in particular are more likely to see themselves in direct labour market competition with migrants. In this section we look at the role that macro-economic conditions might play in moderating the adverse well-being effects from inflows of foreign-born individuals. Our a priori expectations are that in keeping with the idea of perceived labour market threats being a relevant factor, the estimated negative effect of foreign-born individuals will be relatively more pronounced when macro-economic conditions are less favourable. The intuition being that in times of economic stress (for example, negative or low GDP growth), natives may see net inflows of foreign-born individuals as more of a threat to their own economic security.

As a means to examine this issue, we interacted GDP with foreign-born individuals. The resulting interaction coefficient (GDP*foreign-born individuals) was statistically significant, albeit at $10 \%$ significance level $(0.0031, p=0.092)$ and in Figure 1 we provide a visual illustration of this interaction effect. This Figure plots the relationship between foreign-born individuals and subjective well-being at the highest (3.7) and lowest (-4.3) GDP levels observed during our study period as well as a mid-point of sorts (0). ${ }^{14}$ Parallel lines would indicate that the effect of foreign-born individuals on subjective well-being is not responsive to changes in GDP. We can see in this figure however, that the estimated negative impact of foreign-born individuals on well-being is close to 0 at high levels of GDP but we find that as growth gets lower, the estimated negative effect becomes more and more substantive. In other words, in times of economic stress the negative subjective well-being impact of immigration seems to be more apparent.

\section{Insert figure 1 here}

\section{Social Identity theory}

Drawing on social identity theory, we offer up one further potential explanation as to why foreignborn individuals negatively affects the subjective well-being of natives. The central hypothesis behind this theory is that in order to increase their own self-image, people will often boost the status of their own group (ingroup) and hold prejudiced views against the groups to which they don't belong 
(outgroup) (Tajfel, 1974). In turn, inflows of foreign-born individuals may be seen as threatening the way of life and social identity of natives. Taking this argument one step further, we would expect to see that relative to the group we classified as natives in our earlier analysis (i.e. UK-born individuals), residents born outside the UK would be more likely to see migrants as part of their own ingroup as opposed to outgroup.

Fortunately, our household surveys allows us to identify a sample of current residents living in local authority areas, but born outside the UK. Using this information, we then examined whether foreignborn individuals has a differential impact on the well-being of these residents relative to the group we classified for simplicity as natives (UK-born). In keeping with social identity theory, we would expect that non-UK born residents would be less negatively impacted by immigration than UK-born ones (natives) as they are less likely to see migrants as part of an outgroup. Indeed we found that in contrast to the results we outlined earlier in relation to UK-born natives (Table 2), the subjective well-being of residents born outside the UK appears to be positively enhanced by inflows of migrants $(0.055, p=$ 0.06).

\section{Conclusion}

The main aim of this work was to ascertain if immigration in England was associated with any subjective well-being consequences for natives and, if so, to ascertain which groups were most likely to be impacted. While the labour market impacts of immigration have received substantial coverage in the literature, much less attention has been placed on broader measures of subjective wellbeing. When looking at the population as a whole, we find that inflows of foreign-born individuals into local areas is associated with modest negative impacts on the subjective well-being of UK-born natives. On the other hand, the subjective well-being of residents born outside the UK appears to be positively enhanced by inflows of migrants. An important feature of our analysis is that our findings are robust to two different estimators (panel models with individual-fixed effects and instrumental 
variable approaches) and a series of robustness checks designed to address any remaining concerns surrounding, for example, residential sorting (selection bias). Notwithstanding this point, one potential limitation with this approach is that while we instrument our immigration figure with a predicted value which is estimated using prior settlement patterns, ideally one would exploit a natural experiment as an instrumental variable (e.g. a labour market shock which neatly identifies a treatment and a control group). Identifying such an instrumental variable will be challenging but a useful avenue for future work.

A further important feature of our analysis is that we illustrate how focusing on 'average' or put differently main effects will mask substantive differences across socioeconomic and sociodemographic groups when it comes to the impact of immigration on the subjective well-being of natives. Specifically, certain sub-groups such as the relatively elderly, the unemployed and more broadly the less well-off appear much more likely to experience a reduction in subjective well-being in response to inflows of migrants than others. It is notable that there is a significant degree of similarity between these well-being differentials across distinct cohorts of the population, and voting patterns (for example, see Ipsos 2016) observed in the recent UK referendum on EU membership (commonly referred to as Brexit). In light of this, one useful avenue for future work would be to unpick to what extent voting patterns evident in the recent UK referendum and indeed other referendums can be attributable to well-being differentials across socioeconomic and sociodemographic groups.

An additional novel feature of our work is that we point to two potential channels, namely perceived labour market competition and social identity that can aid our understanding of how immigration may influence the subjective well-being of natives. Regarding perceived labour market competition, our argument rests on the idea that while objective evidence would point to negligible, if any, negative impacts on employment outcomes for natives in the UK (and evidence would point to positive effects for the wage distribution as a whole), public perception may differ. Indeed a cursory examination of 
the popular press in the UK would suggest that, for large sections of the public at least, immigration is often associated with negative effects on the employment opportunities for natives. This, we suggest, could lead to certain cohorts viewing rising net inflows of foreign-born individuals as an economic threat. In support of this premise, we find that the negative relationship between net inflows of foreign-born individuals and well-being is more pronounced when macro-economic conditions are less favourable. The intuition being that in times of economic stress (for example, negative or low GDP growth), perceived economic threats will be more apparent to natives.

In further support of this point related to the potential for perceived labour market impacts to be a factor, it is perhaps worth highlighting some interesting recent work published in this journal which suggests that due to what the authors describe as 'ethnic penalties', there may be a prevalence of over-qualification when it comes to the presence of migrants from the A8 accession countries in the workforce (Sirkeci et al., 2018). Additionally, at least in the short run, there is evidence that A8 migrant workers record substantially lower absence rates than native workers (Dawson et al., 2018). All this may help fuel a perception on the part of natives that migrants are an economic threat (regardless of whether this is actually true in practice or not).

We draw on social identity theory as a further proposed explanation for the observed adverse wellbeing impact from immigration. Social identity theory suggests that ethnic groups can form the basis for self-categorization and emotional attachment, and thus foster psychological well-being (e.g. Phinney et al., 2001). Here we argue that immigration may serve to dilute the ethnic characteristics of the native ingroup as migrants may be seen as an outgroup by natives and thus looked on less favourably. Thus, for natives with a relatively strong sense of national identity, increased immigration may be seen as a cultural threat, as opposed to merely an economic one. 
To conclude, our findings suggest that inflows of foreign-born individuals into local areas in England negatively affects the well-being of UK-born natives, but that these effects differ sharply across sociodemographic groupings. Even if objective evidence would suggest that rising levels of immigration does not negatively affect the economic outcomes of natives, if immigration is associated with adverse effects on the subjective well-being of certain groups in society, then this makes the challenge of integration between natives and migrants more difficult. In such circumstances, it becomes important not just to determine which groups are adversely affected by immigration, but also what can explain these effects. In this study, we point to two potential mechanisms that warrants further investigation when it comes to understanding the dynamics between immigration and subjective well-being, namely perceived labour market competition and social identity.

\footnotetext{
${ }^{1}$ The A8 countries (Czech Republic, Estonia, Hungary, Latvia, Lithuania, Poland, Slovakia, Slovenia) plus Malta and Cyprus were allowed access to the UK from 2004.

${ }^{2}$ We note that there is some research to suggest that inflows of migrants may have negative effects on the wages of relatively low-skilled workers (see Borjas, 2003)

${ }^{3}$ They are 9 regions in England (12 in the UK as a whole) and they define areas (constituencies) for the purposes of elections to the European Parliament.

${ }^{4}$ Interviews from each wave span over two and in some cases three years

${ }^{5}$ Findings are robust to clustering at the local authority level

${ }^{6}$ We focus on England as opposed to the UK as one of our key control variables - Indices of Multiple Deprivation - are only available for Local Authority Districts in England. The sample excludes people aged 18 or less.

${ }^{7}$ In order to assess whether the difference of coefficients from separate regressions is statistically different we employ the standard $z$ statistics $Z=\left(b_{1}-b_{2}\right) / \sqrt{\left(S E b_{1}\right)^{2}-\left(S E b_{2}\right)^{2}}$, which is valid in large samples (Clogg et al., 1995 but see also Gelman and Stern, 2006).

${ }^{8}$ We selected 60 or under as the reference category but we observe similar findings (i.e., no significant effects) if we select younger age cohorts too.

${ }^{9}$ The difference of the estimated effects of foreign-born individuals between individuals in the lowest income quartile is statistically different from individuals with above median income (at $5 \%$ level).

${ }^{10}$ The difference between both coefficients is statistically significant at $5 \%$ level.

${ }^{11}$ The first stage regression estimate of our predicted migrants variable is 0.85 ( $\left.p<0.001\right)$. The F-stat is 40692 .

12 Results do not change in any meaningful fashion if we for example look at the 2009-2007 or 2011-2017 period.

${ }^{13}$ To aid interpretation we multiplied this ratio by 100 so that the coefficients capture the estimated impact of a $1 \%$ increase in the migrant share.

${ }^{14}$ The same picture emerges if we select different levels of GDP as our benchmark levels
} 


\section{References}

Akay A, Constant A and Giulietti C (2014) The impact of immigration on the well-being of natives. Journal of Economic Behavior and Organization 103: 72-92.

Akay A, Constant A, Giulietti C and Guzi M (2017) Ethnic diversity and well-being. Journal of Population Economics 30(1): 265-306.

Bell B, Fasani F and Machin S (2013) Crime and immigration: Evidence from large immigrant waves. Review of Economics and Statistics 95(4): 1278-1290.

Borjas GJ (2003) The labor demand curve is downward sloping: Re-examining the impact of immigration on the labor market. Quarterly Journal of Economics 118 (4): 1335-1374.

Braakmann N (2019) Immigration and the property market: Evidence from England and Wales. Real Estate Economics 47(2): 509-533.

Card D (2001) Immigrant inflows, native outflows, and the local labor market impacts of higher immigration. Journal of Labor Economics 19(1): 22-63.

Card D (2005) Is the new immigration really so bad? NBER Working Paper 11547. Cambridge MA: National Bureau of Economic Research.

Card D and DiNardo J (2000) Do immigrant inflows lead to native outflows? American Economic Review 90(2): 360-367.

Clogg CC, Petkova E and Haritou A (1995) Statistical methods for comparing regression coefficients between models. American Journal of Sociology 100(5): 1261-1293.

Dawson C, Veliziotis M and Hopkins B (2018) Understanding the perception of the 'Migrant Work Ethic. Work, Employment and Society 32(5): 811-830.

Department of Communities and Local Government (2015) The English Indices of Deprivation. Available at: https://assets.publishing.service.gov.uk/government/uploads/system/uploads/attachment data/file $464597 /$ English Indices of Deprivation 2015 - Research Report.pdf

Dolan P, Peasgood T and White M (2008) Do we really know what makes us happy? A review of the economic literature on the factors associated with subjective well-Being. Journal of Economic Psychology 29(1): 94-122.

Dustmann C and Frattini T (2014) The fiscal effects of immigration to the UK. The Economic Journal 124(580): F593-F643.

Dustmann C, Frattini T and Halls (2010) Assessing the fiscal costs and benefits of A8 migration to the UK. Fiscal Studies 31 (1): 1-41.

Dustmann C, Frattini T and Preston I (2013) The effect of immigration along the distribution of wages. The Review of Economic Studies 80(1): 145-173. 
Gelman A and Stern H (2006) The difference between "significant" and "not significant" is not itself statistically significant. The American Statistician 60(4): 328-331.

Giulietti C (2017) Immigration and happiness. Available (Accessed 29 January 2019) at: http://ukandeu.ac.uk/immigration-andhappiness-in-the-uk/

Giuntella O, Mazzonna F, Nicodemo C and and Vargas-Silva C (2016) Immigration and the reallocation of work health risks. IZA Discussion Paper no. 10304.

Goldberg DP and Hillier VF (1979) A scaled version of the General Health Questionnaire. Psychological Medicine 9(1): 139-145.

Haslam SA, Jetten J, Postmes T and Haslam C (2009) Social identity, health and well-being: An emerging agenda for applied psychology. Applied Psychology: An International Review 58(1): 1-23.

Hobolt SB (2016) The Brexit vote: A divided nation, a divided continent. Journal of European Public Policy 23(9): 1259-1277.

Ipsos MORI (2016) How Britain voted in the 2016 EU referendum. Available (Accessed 29 January 2019) at: https://www.ipsos.com/ipsos-mori/en-uk/how-britain-voted-2016-eu-referendum

IvLevs A and Velisiotis M (2018) Local-level immigration and life satisfaction: The EU enlargement experience in England and Wales. Environment and Planning A: Economy and Space 50(1): 175-193.

Kamerāde D and Bennett MR (2018) Rewarding work: Cross-national differences in benefits, volunteering during unemployment, well-being and mental health. Work, Employment and Society 32(1): 38-56.

Lemos S and Portes J (2013) New labour? The effects of migration from Central and Eastern Europe on unemployment and wages in the UK. The B.E. Journal of Economic Analysis and Policy 14(1): 299338.

Mangum M and Block RJ (2018) Social identity theory and public opinion towards immigration. Social Sciences 7(3): 41.

Nordenmark M (1999) Non-financial employment motivation and well-being in different labour market situations: A longitudinal study. Work, Employment and Society 13(4): 601-620.

ONS (2018) Population of the UK by country of birth and nationality. Available (Accessed 3 May 2018) at:

https://www.ons.gov.uk/peoplepopulationandcommunity/populationandmigration/internationalmi gration/datasets/populationoftheunitedkingdombycountryofbirthandnationality

Phinney JS, Horenczyk G, Liebkind K and Vedder P (2001) Ethnic identity, immigration, and wellbeing: An interactional perspective. Journal of Social Issues 57(3): 493-510.

Sa F (2015) Immigration and house prices in the UK. The Economic Journal 125(587): 1393-1424.

Sirkeci I, Acik N, Saunders B and Prívara A (2018) Barriers for highly qualified A8 immigrants in the UK labour market. Work, Employment and Society 32(5): 906-924. 
Strandh M (2000) Different exit routes from unemployment and their impact on mental well-being: The role of the economic situation and the predictability of the life course. Work, Employment and Society 14(3): 459-479.

Tajfel H (1974) Social identity and intergroup behaviour. Information (International Social Science Council) 13(2): 65-93.

van der Zee K, Benet-Martínez V and van Oudenhoven JP (2016) Personality and acculturation. In: The Cambridge Handbook of Acculturation Psychology, Second Edition, pp. 50-70. Cambridge: Cambridge University Press. 
Figure 1: The extent to which the effect of foreign-born individuals varies according to changes in GDP

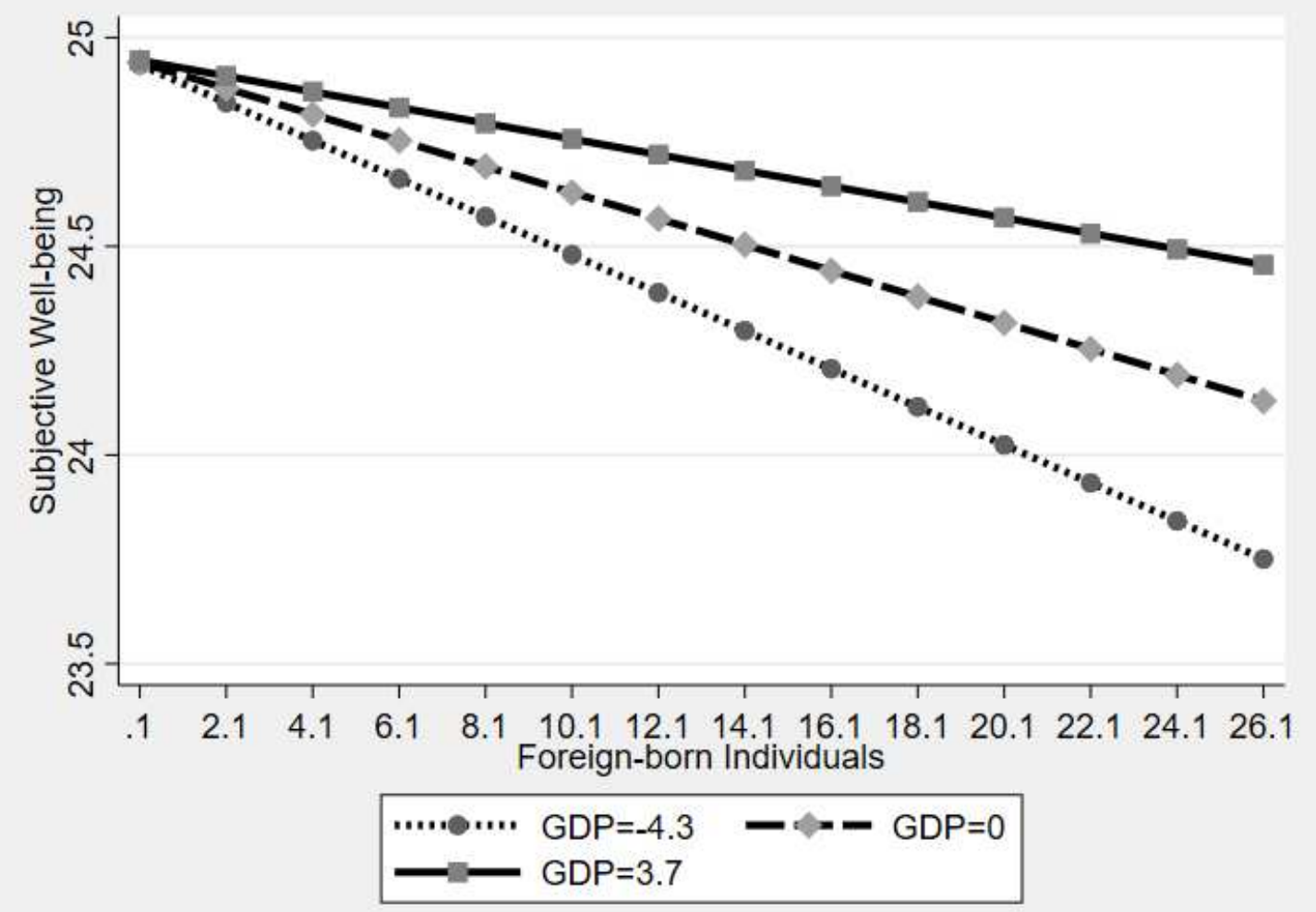

Note: Foreign-born individuals are in 000's

Source: Figure created in Stata (a statistical software package) by the authors outlining the interaction effect between foreign-born individuals and GDP. 
Table 1: The relationship between subjective well-being (GHQ) and foreign-born individuals

\begin{tabular}{lccc}
\hline & Pooled OLS & Fixed-effects & IV \\
\hline Foreign-born individuals & & & $-0.032^{* *}$ \\
(00,000s) & 0.003 & $-0.025^{*}$ & $(0.013)$ \\
& $(0.004)$ & $(0.013)$ & Yes \\
Individual characteristics & & & Yes \\
Index of Deprivation & Yes & Yes & Yes \\
Wave dummies & Yes & Yes & Yes \\
GDP & Yes & Yes & Yes \\
Regional dummies & Yes & Yes & 214,610 \\
& Yes & & 214,610 \\
\hline
\end{tabular}

Notes: This table reports coefficients from regressions of individual subjective well-being (GHQ) on number of foreign-born individuals within the local authority of residence. Each regression controls for individual characteristics (age, age-squared, educational attainment dummies, gender, gross household income, marital status, number of children, labour force status dummies), the local authority deprivation rank, annual GDP growth at national level, wave and regional dummies. The second column labelled Fixed-effects include individual fixed-effects. The third column reports estimates of a regression in which the variable foreign-born individuals has been instrumented using a variable derived based on an analysis of past settlement patterns by migrants. The full set of estimates can be found in Table A5 in the appendix. Standard errors in parenthesis are clustered at the individual level. ${ }^{*}$ statistically significant at $10 \%$ level, $* *$ significant at $5 \%$ level, $* * *$ significant at $1 \%$ level. 
Table 2: The relationship between subjective well-being (GHQ) and foreign-born individuals and the relationship between subjective well-being (GHQ) and migrant share - analysis of differences across sub-groups

\begin{tabular}{|c|c|c|c|c|c|c|}
\hline & \multicolumn{4}{|c|}{ Foreign-born individuals } & \multicolumn{2}{|c|}{ Migrant share } \\
\hline & \multicolumn{2}{|c|}{$\underline{\text { Fixed-effects }}$} & \multicolumn{2}{|c|}{ IV } & \multicolumn{2}{|c|}{$\underline{\mathrm{IV}}$} \\
\hline & Coef. & $\begin{array}{l}\text { Clustered } \\
\text { Std. Err. }\end{array}$ & Coef. & Std. Err & Coef. & Std. Err \\
\hline \multicolumn{7}{|c|}{ Age } \\
\hline Age $<=60$ & -0.009 & 0.014 & -0.011 & 0.015 & -0.008 & 0.011 \\
\hline Age $>60$ & $-0.084 * * *$ & 0.031 & $-0.116 * * *$ & 0.035 & $-0.071 * * *$ & 0.022 \\
\hline Age $>70$ & $-0.142 * * *$ & 0.045 & $-0.183 * * *$ & 0.052 & $-0.128 * * *$ & 0.036 \\
\hline \multicolumn{7}{|c|}{ Household income (quartiles) } \\
\hline Lowest $25 \%$ & $-0.062 * *$ & 0.032 & $-0.100 * * *$ & 0.034 & $-0.079 * * *$ & 0.027 \\
\hline Lowest $50 \%$ & $-0.038^{*}$ & 0.021 & $-0.069 * * *$ & 0.022 & $-0.052 * * *$ & 0.017 \\
\hline Highest 50\% & -0.016 & 0.019 & -0.009 & 0.019 & -0.006 & 0.013 \\
\hline Highest 25\% & -0.016 & 0.026 & 0.001 & 0.028 & 0.001 & 0.018 \\
\hline \multicolumn{7}{|c|}{ Education } \\
\hline Degree Education & -0.007 & 0.018 & -0.008 & 0.020 & -0.006 & 0.014 \\
\hline Secondary Education & 0.001 & 0.022 & -0.024 & 0.022 & -0.016 & 0.015 \\
\hline Other Education & -0.056 & 0.050 & -0.043 & 0.057 & -0.034 & 0.044 \\
\hline No formal qualifications & $-0.138 * * *$ & 0.042 & $-0.137 * * *$ & 0.046 & $-0.113^{* * *}$ & 0.039 \\
\hline \multicolumn{7}{|c|}{ Gender } \\
\hline Males & -0.018 & 0.018 & $-0.031^{*}$ & 0.018 & $-0.021^{*}$ & 0.012 \\
\hline Females & -0.031 & 0.019 & $-0.031^{*}$ & 0.019 & $0.023 *$ & 0.014 \\
\hline \multicolumn{7}{|c|}{ Labour market status } \\
\hline Unemployed & $-0.146^{*}$ & 0.080 & $-0.214^{*}$ & 0.114 & $-0.225^{*}$ & 0.120 \\
\hline Employed & -0.010 & 0.017 & -0.011 & 0.017 & -0.008 & 0.012 \\
\hline \multicolumn{7}{|c|}{ Natives v non-UK born } \\
\hline Non-UK born & $0.055^{*}$ & 0.029 & $0.058^{*}$ & 0.030 & $0.038 *$ & 0.020 \\
\hline Natives & $-0.025^{*}$ & 0.013 & $-0.032 * *$ & 0.013 & $-0.022^{* *}$ & 0.009 \\
\hline
\end{tabular}

Notes: Each cell reports coefficients or standard errors of foreign-born individuals from separate subjective wellbeing (GHQ) regressions on specific sub-groups. Each regression controls for individual characteristics (age, agesquared, educational attainment dummies, gender, gross household income, marital status, number of children, labour force status dummies), the local authority deprivation rank, annual GDP growth at national level, wave and region dummies. IV refers to an instrumental variable specification in which the variable foreign-born individuals has been instrumented using a variable derived based on an analysis of past settlement patterns by migrants. *statistically significant at $10 \%$ level, ${ }^{* *}$ significant at $5 \%$ level, ${ }^{* * *}$ significant at $1 \%$ level 


\section{Online Appendix}

Table A1: GHQ components

Lost much sleep over worry?

Felt constantly under strain?

Felt that you could not overcome your difficulties?

Been feeling unhappy and depressed?

Been able to concentrate on whatever you are doing?

Felt that you were playing a useful part in things?

Felt capable of making decisions about things?

Been able to enjoy your normal day-to-day activities?

Been able to face up to your problems?

Been feeling reasonably happy, all things considered?

Been losing self-confidence in yourself?

Been thinking of yourself as a worthless person?

Figure A1: Total number of foreign-born individuals in UK and England over $2000-2017(00,000$ s)

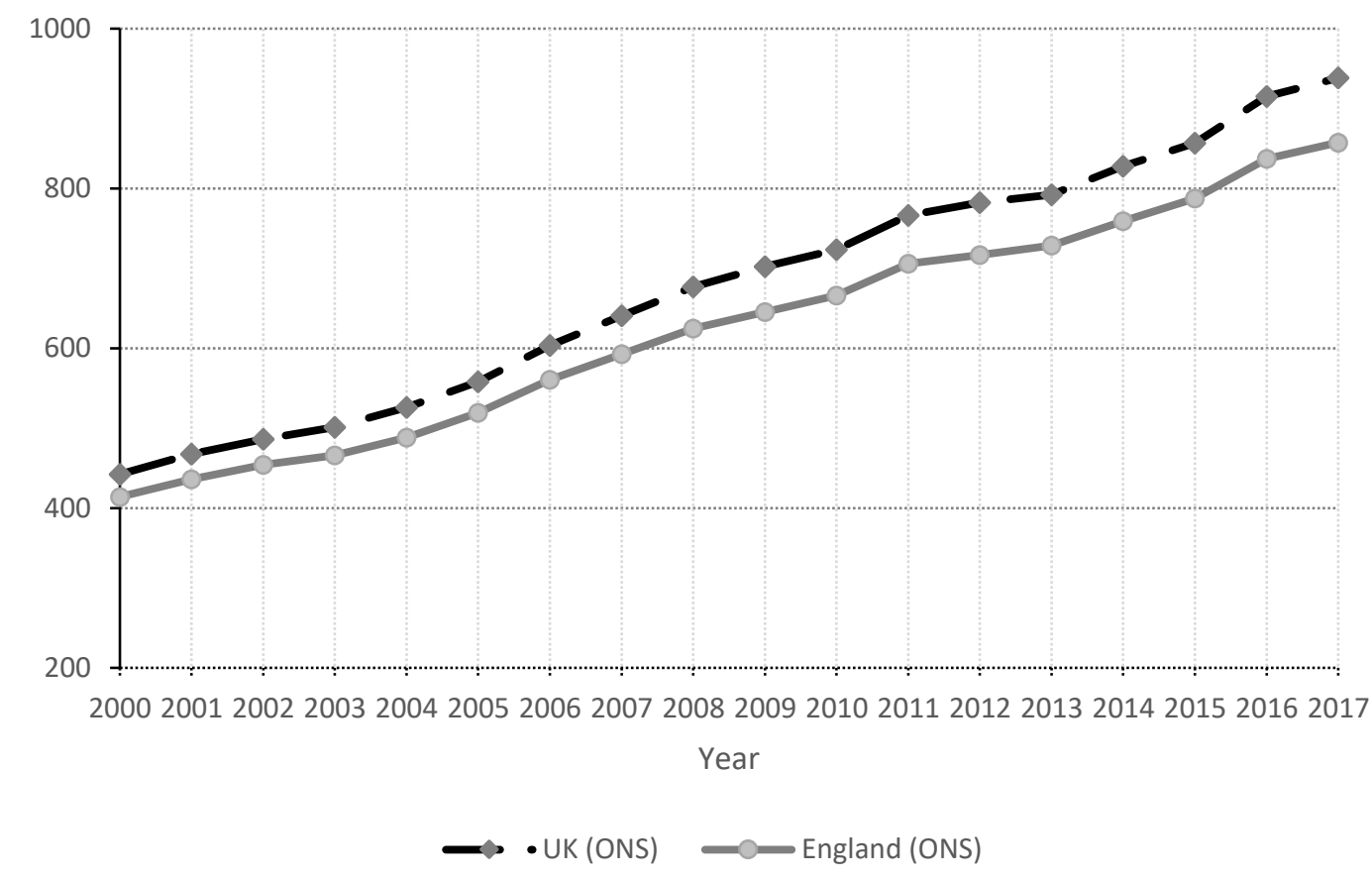

Source: Data came from the Office for National Statistics (ONS, 2018) 


\section{A2 Indices of Multiple Deprivation}

We merged our household survey datasets with the English Indices of Multiple Deprivation provided by the Department for Communities and Local Government. ${ }^{1}$ These Indices of Multiple Deprivation rank each neighbourhood in England according to seven distinct measures of deprivation. The specific deprivation rankings include Income; Employment; Health and Disability; Education, Skills and Training; Crime; Barriers to Housing and Services; and Living Environment. In addition to these specific rankings, the Department for Communities and Local Government publish an amalgamated measure reflecting the overall level of deprivation in each neighbourhood. We include this amalgamated deprivation ranking as an additional covariate in order to control for any differences in the economic and social conditions across local authority areas. ${ }^{2}$ These indices are published at regular intervals, i.e., 2004, 2007, 2010 and $2015 .^{3}$ We extrapolated and interpolated across these intervals to obtain a measure of neighbourhood deprivation for each year of our analysis and added the resulting deprivation measure as a control variable.

\footnotetext{
${ }^{1}$ See DCLG (2015) for more details.

${ }^{2}$ Results are robust to different combinations of these neighbourhood level control variables

${ }^{3}$ The indices are published in 2004, 2007, 2010 and 2015. However they typically capture information from neighbourhoods in 2002, 2005, 2008 and 2013. In addition to a relative ranking across neighbourhoods the DCLG also publish scores for each neighbourhood but these scores in contrast to the ranks are not directly comparable over time, and so are not used in the analysis.
} 
Table A3: Summary statistics of the sample used in main models in table $1(N=214,610)$

\begin{tabular}{|c|c|c|c|c|}
\hline Variable & Mean & Std. Dev. & Min & Max \\
\hline Subjective well-being & 24.87 & 5.45 & 0 & 36 \\
\hline Foreign-born individuals & 28064 & 38854 & 1000 & 268000 \\
\hline Age & 48.79 & 17.55 & 19 & 102 \\
\hline Age squared & 2688.17 & 1804.19 & 361 & 10404 \\
\hline Other degree & 0.11 & 0.32 & 0 & 1 \\
\hline Degree & 0.22 & 0.41 & 0 & 1 \\
\hline A-levels & 0.21 & 0.41 & 0 & 1 \\
\hline GCSE & 0.22 & 0.42 & 0 & 1 \\
\hline Other & 0.10 & 0.31 & 0 & 1 \\
\hline No formal qualifications & 0.14 & 0.34 & 0 & 1 \\
\hline Male & 0.45 & 0.50 & 0 & 1 \\
\hline Household income & 3530.05 & 2780.37 & -20000 & 86703.29 \\
\hline Single & 0.18 & 0.38 & 0 & 1 \\
\hline Married & 0.67 & 0.47 & 0 & 1 \\
\hline Divorced & 0.08 & 0.28 & 0 & 1 \\
\hline Widowed & 0.06 & 0.24 & 0 & 1 \\
\hline Number of children & 0.53 & 0.93 & 0 & 9 \\
\hline Self-employed & 0.08 & 0.27 & 0 & 1 \\
\hline Paid employment & 0.52 & 0.50 & 0 & 1 \\
\hline Unemployed & 0.04 & 0.20 & 0 & 1 \\
\hline Inactive & 0.36 & 0.48 & 0 & 1 \\
\hline Local-authority deprivation rank & 17120.98 & 9164.41 & 1 & 32842 \\
\hline National GDP & 1.74 & 1.68 & -4.3 & 3.7 \\
\hline North West Region & 0.14 & 0.35 & 0 & 1 \\
\hline Yorkshire & 0.11 & 0.31 & 0 & 1 \\
\hline East Midlands & 0.10 & 0.30 & 0 & 1 \\
\hline West Midlands & 0.11 & 0.31 & 0 & 1 \\
\hline East of England & 0.11 & 0.31 & 0 & 1 \\
\hline London & 0.10 & 0.29 & 0 & 1 \\
\hline South East England & 0.17 & 0.37 & 0 & 1 \\
\hline South West England & 0.12 & 0.32 & 0 & 1 \\
\hline
\end{tabular}

Notes: Subjective well-being (GHQ) and individual characteristics are from BHPS and UKHLS (2000 - 2017). The number of foreign-born individuals at local authority level over $2000-2017$ is from the ONS. 


\section{A4 Derivation of Instrument variables}

We relied on an instrumental variable strategy based on past settlement patterns first developed by Card and DiNardo (2000) and Card (2001) and subsequently widely used in the immigration literature. For instance, focusing specifically on the UK context, Bell et al. (2013), Sa (2011), Braakman (2019) and Giuntella et al. (2016) have recently employed this instrumental variable approach to examine the impact of immigration on crime, house prices and work injury respectively. The central idea behind this instrument is that irrespective of the economic characteristics of neighbourhoods, migrants will be more likely to locate in certain areas over others based on the prior settlement patterns of past migrants. We can therefore exploit the settlement patterns evident from a past Census to generate an exogenous predicted 'migration' value that can serve as an instrument for current inflows.

To implement this approach in our study, first we obtained data relating to the concentration of migrants in each local authority area from the 2001 and 2011 Censuses. Next we use this information to obtain the 'predicted' numbers or share of foreign-born individuals in each local authority area to use as an instrument for the actual number or share of foreign-born individuals. The predicted number or share of migrants in each local authority area is simply obtained by redistributing the total numbers or share of migrants across local authority areas, based on prior settlement patterns, i.e., the migrant share evident from the 2001 and 2011 censuses respectively. ${ }^{4}$

To illustrate how we obtained the predicted number or share in practice, consider a local authority that had $1 \%$ of all foreign-born individuals according to the 2001 census and $2 \%$ according to the 2011 census. In the years between 2001 and 2011, the local authority would be allocated 1\% of all new arrivals and post they would be allocated $2 \%$. This would then serve as our 'predicted' value. In short, we are exploiting exogenous variation generated by prior settlement patterns of migrants. We also derived an additional predicted number of migrants figure by just using the $2001^{5}$ census figures which we employ as an additional sensitivity check.

A potential threat to the validity of using these 'predicted' values as an instrumental variable is if local economic shocks which initially attracted migrants persist over time as these may be correlated with individual well-being. This potential problem is substantially mitigated in our analysis by including fixed-effects as well as wave dummies (which will account for any trends) a measure of national GDP, region dummies and time-varying local controls such as neighbourhood deprivation

\footnotetext{
${ }^{4}$ For years pre 2011 we redistribute the total number of migrants based on the 2001 census figures (we use actual ONS values for 2000 and actual census values for 2001). For years post 2011 we redistribute based on the figures obtained from the 2011 census (and use actual census values for 2011). Results do not change if we drop observations from 2000 and 2001 from the analysis.

${ }^{5}$ Unfortunately it is not possible to use earlier census figures as boundaries have changed.
} 
Table A5: The relationship between subjective well-being (GHQ) and foreign-born individuals - full estimates of the analysis presented in table 1

\begin{tabular}{|c|c|c|c|}
\hline & Pooled OLS & Fixed-effects & IV \\
\hline Foreign-born individuals $(00,000)$ & $\begin{array}{c}0.003 \\
(0.004)\end{array}$ & $\begin{array}{c}-0.025^{*} \\
(0.013)\end{array}$ & $\begin{array}{c}-0.032 * * \\
(0.013)\end{array}$ \\
\hline Age & $\begin{array}{c}-0.150 * * * \\
(0.005)\end{array}$ & $\begin{array}{c}-0.145^{* * *} \\
(0.050)\end{array}$ & $\begin{array}{c}-0.144 * * * \\
(0.043)\end{array}$ \\
\hline Age-squared & $\begin{array}{c}0.002 * * * \\
(0.000)\end{array}$ & $\begin{array}{c}0.001 * * * \\
(0.000)\end{array}$ & $\begin{array}{c}0.001^{* * *} \\
(0.000)\end{array}$ \\
\hline Other higher degree & $\begin{array}{c}0.454^{* * *} \\
(0.050)\end{array}$ & $\begin{array}{c}0.104 \\
(0.325)\end{array}$ & $\begin{array}{c}0.104 \\
(0.242)\end{array}$ \\
\hline Degree & $\begin{array}{c}0.488 * * * \\
(0.047)\end{array}$ & $\begin{array}{l}-0.163 \\
(0.320)\end{array}$ & $\begin{array}{l}-0.162 \\
(0.231)\end{array}$ \\
\hline Higher secondary qualification (A-level) & $\begin{array}{c}0.473 * * * \\
(0.046)\end{array}$ & $\begin{array}{c}0.246 \\
(0.300)\end{array}$ & $\begin{array}{c}0.247 \\
(0.213)\end{array}$ \\
\hline Lower secondary qualification (GCSE) & $\begin{array}{c}0.466 * * * \\
(0.044)\end{array}$ & $\begin{array}{c}0.192 \\
(0.284)\end{array}$ & $\begin{array}{c}0.192 \\
(0.203)\end{array}$ \\
\hline Other & $\begin{array}{c}0.331 * * * \\
(0.050)\end{array}$ & $\begin{array}{l}-0.170 \\
(0.239)\end{array}$ & $\begin{array}{l}-0.169 \\
(0.179)\end{array}$ \\
\hline Male & $\begin{array}{c}0.944 * * * \\
(0.024)\end{array}$ & & \\
\hline Household income $(£ 0,000)$ & $\begin{array}{c}0.000 * * * \\
(0.000)\end{array}$ & $\begin{array}{l}0.000^{*} \\
(0.000)\end{array}$ & $\begin{array}{c}0.000^{* *} \\
(0.000)\end{array}$ \\
\hline Married & $\begin{array}{c}0.263 * * * \\
(0.040)\end{array}$ & $\begin{array}{c}0.203^{* *} \\
(0.088)\end{array}$ & $\begin{array}{c}0.203 * * * \\
(0.069)\end{array}$ \\
\hline Divorced & $\begin{array}{c}-0.885^{* * *} \\
(0.061)\end{array}$ & $\begin{array}{c}-0.396 * * * \\
(0.132)\end{array}$ & $\begin{array}{c}-0.396^{* * *} \\
(0.098)\end{array}$ \\
\hline Widowed & $\begin{array}{c}-0.598 * * * \\
(0.066)\end{array}$ & $\begin{array}{c}-0.854^{* * *} \\
(0.167)\end{array}$ & $\begin{array}{c}-0.853^{* * *} \\
(0.126)\end{array}$ \\
\hline Number of children & $\begin{array}{c}-0.020 \\
(0.015)\end{array}$ & $\begin{array}{c}-0.005 \\
(0.032)\end{array}$ & $\begin{array}{l}-0.005 \\
(0.024)\end{array}$ \\
\hline Self-employed & $\begin{array}{c}0.106 * * * \\
(0.040)\end{array}$ & $\begin{array}{c}0.087 \\
(0.068)\end{array}$ & $\begin{array}{c}0.087 \\
(0.061)\end{array}$ \\
\hline Unemployed & $\begin{array}{c}-2.479 * * * \\
(0.076)\end{array}$ & $\begin{array}{c}-1.677^{* * *} \\
(0.089)\end{array}$ & $\begin{array}{c}-1.677^{* * *} \\
(0.064)\end{array}$ \\
\hline Inactive & $\begin{array}{c}-1.343^{* * *} \\
(0.036)\end{array}$ & $\begin{array}{c}-0.528 * * * \\
(0.061)\end{array}$ & $\begin{array}{c}-0.529 * * * \\
0.087\end{array}$ \\
\hline Local authority deprivation rank & $\begin{array}{c}0.000 * * * \\
(0.000)\end{array}$ & $\begin{array}{c}0.000 \\
(0.000)\end{array}$ & $\begin{array}{c}0.000 \\
(0.000)\end{array}$ \\
\hline National GDP & $\begin{array}{c}0.009 \\
(0.010) \\
0.000 * * *\end{array}$ & $\begin{array}{c}0.009 \\
(0.009) \\
0.000\end{array}$ & $\begin{array}{c}0.009 \\
(0.010) \\
0.000\end{array}$ \\
\hline $\begin{array}{l}\text { Wave dummies } \\
\text { Region dummies }\end{array}$ & Yes & Yes & Yes \\
\hline Region dummies & Yes & Yes & Yes \\
\hline Observations & 214,610 & 214,610 & 214,610 \\
\hline
\end{tabular}




\section{A6: Selection bias}

Notwithstanding the longitudinal nature of our analysis it is still perhaps instructive to discuss the potential for selection bias due to residential sorting on the part of natives or migrants to affect our estimates. When it comes to migrants, one could reasonably conjecture that settlement patterns of migrants and the subjective well-being of natives could both be partly driven by the overall prosperity of an area. Our main specification should mitigate against this possibility in that the effect of inflows of foreign-born individuals on subjective well-being is identified only when it changes for the same individual, and after controlling for a rich-set of time-varying factors at both the individual and at the neighbourhood level (e.g. English indices of deprivation are added as controls to our specification).

A further possibility is if natives who are relatively more adversely affected by inflows of foreign-born individuals move to a residential area with less migrants, then this would undermine our ability to precisely estimate the effect of foreign-born individuals. As a means to gauge the likely importance of this factor, we can look at what factors are related with the probability of individuals moving in our sample. To facilitate this, using a special licence application we obtained the specific neighbourhood each individual in our sample resides in ${ }^{6}$ at each interview date. We then derived a simple binary indicator which captures whether individuals have switched neighbourhoods between waves. We identified 16,918 individual-wave observations and examined what factors are related with the probability of individuals changing their neighbourhood between waves using both a pooled crosssectional logit as well as a fixed-effects panel logit model. We did not find any significant relationship between net inflows of foreign-born individuals and the probability of observing neighbourhood changes in our sample. The coefficient estimate was close to zero and not close to being statistically significant in either our fixed effects or pooled logit model ${ }^{7}$. This is in keeping with the literature underpinning residential mobility which suggests that factors such as age, life cycle stage and employment opportunities are the major factors underpinning residential moves.

In order to further strengthen the causal interpretation of our results, we conducted two further robustness checks which seek to mitigate any bias due to residential self-selection. The first is that we repeated the analysis in Table 1 but added an additional covariate representing those individuals who have moved neighbourhoods during our study period. The second robustness check is that we simply

\footnotetext{
${ }^{6}$ Neighbourhoods here are defined at the lower super output area. These are at a very spatially refined scale as there is an average of just 1500 respondents in each lower super output area and over 32,000 of these in the UK.

${ }^{7}$ Coefficient estimate from our pooled logit $(0.002, p=0.452)$ and from our panel $(0.005, p=0.470)$.
} 
excluded all individuals who have moved neighbourhoods from our analysis. The coefficient estimates are very stable under both scenarios ${ }^{8}$.

${ }^{8}$ When adding an additional dummy variable for movers, the coefficient for foreign-born individuals is -0.027 $(p=0.036)$. When excluding movers ( $8 \%$ of the sample) the coefficient estimate is again very similar $(-0.023, p$ $=0.17)$. This compares to an estimate of $-0.025(p=0.054)$ in table 1 . 
Table A7: The relationship between subjective well-being (GHQ) and foreign-born individuals and the relationship between subjective well-being (GHQ) and migrant share - analysis of differences across sub-groups: Comparison of IV based on 2001/2011 Censuses vs. IV based on only 2001 Census

\begin{tabular}{|c|c|c|c|c|c|c|c|c|}
\hline & \multicolumn{4}{|c|}{ Foreign-born individuals } & \multicolumn{4}{|c|}{ Migrant share } \\
\hline & \multicolumn{2}{|c|}{ IV $2001 / 2011$} & \multicolumn{2}{|l|}{ IV 2001} & \multicolumn{2}{|c|}{ IV 2001/2011 } & \multicolumn{2}{|l|}{ IV 2001} \\
\hline & Coef. & $\begin{array}{l}\text { Clustered } \\
\text { Std. Err. }\end{array}$ & Coef. & $\begin{array}{l}\text { Std. } \\
\text { Err }\end{array}$ & Coef. & $\begin{array}{l}\text { Std. } \\
\text { Err }\end{array}$ & Coef. & Std. Err \\
\hline \multicolumn{9}{|c|}{ Age } \\
\hline Age $<=60$ & -0.011 & 0.015 & -0.006 & 0.018 & -0.008 & 0.011 & -0.005 & 0.014 \\
\hline Age $>60$ & $-0.116 * * *$ & 0.035 & -0.064 & 0.043 & $-0.071 * * *$ & 0.022 & -0.046 & 0.032 \\
\hline Age $>70$ & $-0.183^{* * *}$ & 0.052 & $-0.123^{*}$ & 0.066 & $-0.128 * * *$ & 0.036 & $-0.097^{*}$ & 0.053 \\
\hline \multicolumn{9}{|c|}{ Household income (quartiles) } \\
\hline Lowest $25 \%$ & $-0.100 * * *$ & 0.034 & -0.051 & 0.042 & $-0.079 * * *$ & 0.027 & -0.045 & 0.037 \\
\hline Lowest $50 \%$ & $-0.069 * * *$ & 0.022 & $-0.060 * *$ & 0.027 & $-0.052 * * *$ & 0.017 & $-0.051 * *$ & 0.023 \\
\hline Highest 50\% & -0.009 & 0.019 & -0.002 & 0.023 & -0.006 & 0.013 & -0.001 & 0.017 \\
\hline Highest 25\% & 0.001 & 0.028 & -0.014 & 0.034 & 0.001 & 0.018 & -0.010 & 0.025 \\
\hline \multicolumn{9}{|c|}{ Education } \\
\hline $\begin{array}{l}\text { Degree } \\
\text { Education }\end{array}$ & -0.008 & 0.020 & 0.002 & 0.023 & -0.006 & 0.014 & 0.002 & 0.019 \\
\hline $\begin{array}{l}\text { Secondary } \\
\text { Education }\end{array}$ & -0.024 & 0.022 & -0.025 & 0.027 & -0.016 & 0.015 & -0.018 & 0.020 \\
\hline $\begin{array}{l}\text { Other } \\
\text { Education }\end{array}$ & -0.043 & 0.057 & -0.006 & 0.068 & -0.034 & 0.044 & -0.006 & 0.063 \\
\hline $\begin{array}{l}\text { No formal } \\
\text { qualifications }\end{array}$ & $-0.137 * * *$ & 0.046 & $-0.112 *$ & 0.057 & $-0.113 * * *$ & 0.039 & $-0.107^{*}$ & 0.055 \\
\hline \multicolumn{9}{|c|}{ Gender } \\
\hline Males & $-0.031^{*}$ & 0.018 & -0.029 & 0.022 & $-0.021 *$ & 0.012 & -0.022 & 0.016 \\
\hline Females & $-0.031^{*}$ & 0.019 & -0.017 & 0.022 & $0.023^{*}$ & 0.014 & -0.014 & 0.018 \\
\hline \multicolumn{9}{|c|}{ Labour market status } \\
\hline Unemployed & $-0.214 *$ & 0.114 & -0.146 & 0.131 & $-0.225^{*}$ & 0.120 & -0.178 & 0.161 \\
\hline Employed & -0.011 & 0.017 & -0.010 & 0.021 & -0.008 & 0.012 & -0.008 & 0.016 \\
\hline \multicolumn{9}{|c|}{ Natives $v$ non-UK born } \\
\hline Non-UK born & $0.058^{*}$ & 0.030 & $0.080 * *$ & 0.035 & $0.038^{*}$ & 0.020 & $0.062 * *$ & 0.028 \\
\hline Natives & $-0.032 * *$ & 0.013 & $-0.027 * *$ & 0.013 & $-0.022 * *$ & 0.009 & $-0.021 * *$ & 0.010 \\
\hline
\end{tabular}

Notes: Each cell reports coefficients or standard errors of foreign-born individuals from separate subjective wellbeing (GHQ) regressions on specific sub-groups. Each regression controls for individual characteristics (age, agesquared, educational attainment dummies, gender, gross household income, marital status dummies, number of children, labour force status dummies), the local authority deprivation rank, annual GDP growth at national level, wave and region dummies. *statistically significant at $10 \%$ level, ${ }^{* *}$ significant at $5 \%$ level, ${ }^{* * *}$ significant at $1 \%$ level 